University of Nebraska - Lincoln

DigitalCommons@University of Nebraska - Lincoln

Faculty Papers and Publications in Animal

Science

Animal Science Department

2002

\title{
Fiber-type composition of muscles of the beef chuck and round
}

K. S. Kirchofer

University of Nebraska-Lincoln

Chris R. Calkins

University of Nebraska-Lincoln, ccalkins1@unl.edu

B. L. Gwartney

University of Nebraska-Lincoln

Follow this and additional works at: https://digitalcommons.unl.edu/animalscifacpub

Part of the Animal Sciences Commons

Kirchofer, K. S.; Calkins, Chris R.; and Gwartney, B. L., "Fiber-type composition of muscles of the beef chuck and round" (2002). Faculty Papers and Publications in Animal Science. 586.

https://digitalcommons.unl.edu/animalscifacpub/586

This Article is brought to you for free and open access by the Animal Science Department at DigitalCommons@University of Nebraska - Lincoln. It has been accepted for inclusion in Faculty Papers and Publications in Animal Science by an authorized administrator of DigitalCommons@University of Nebraska - Lincoln. 


\title{
Fiber-type composition of muscles of the beef chuck and round ${ }^{1}$
}

\author{
K. S. Kirchofer*, C. R. Calkins ${ }^{* 2}$, and B. L. Gwartney $\dagger^{3}$ \\ *Dept. of Animal Science, University of Nebraska, \\ Lincoln, and $\uparrow$ National Cattlemen’s Beef Association, Centennial, CO
}

\begin{abstract}
Thirty-eight muscles of the beef chuck and round were histochemically stained to characterize fiber-type composition in order to facilitate optimal muscle use in value-added products. Select-grade chucks and rounds ( $\mathrm{n}=4$ each) were chosen to represent two carcass weight classes (250 to $295 \mathrm{~kg}$ and 363 to $410 \mathrm{~kg}$ ) and two yield grades (1 and 3). Muscles were sectioned and stained with a procedure that included a succinate dehydrogenase and an adenosine triphosphatase staining technique. Number and diameter of $\beta$-red, $\alpha$-red, and $\alpha$-white muscle fibers were used to determine muscle fiber percentage, muscle fiber area, and percent area in each muscle. Weight did not significantly $(P>0.05)$ affect these muscle fiber-type char-
\end{abstract}

acteristics, probably because of limited sample numbers. Muscles containing greater than $40 \% \beta$-red fibers were classified as red; greater than $40 \% \alpha$-white fibers were classified as white. All other muscles were classified as intermediate. Nine of 12 round muscles were white, including semitendinosus, biceps femoris, rectus femoris, adductor, and semimembranosus. The chuck muscles were red (10 of 26), intermediate (9 of 26), and white ( 7 of 26 ). These data indicate variable fiber-type composition of most of the muscles of the beef chuck and round. Functional and biochemical traits of each muscle fiber class would be expected to create different processing characteristics, which would influence optimal muscle use in value-added products.

Key Words: Beef, Meat, Skeletal Muscle

(C2002 American Society of Animal Science. All rights reserved.

J. Anim. Sci. 2002. 80:2872-2878

\section{Introduction}

There is a relationship between ultimate meat quality and muscle fiber-type composition (Cassens and Cooper, 1971; Ashmore, 1974; Seideman and Theer, 1986). Muscles with increased $\alpha$-white fibers have more connective tissue, less intramuscular fat, and are less tender than muscles with more $\beta$-red fibers (Melton et al., 1974, 1975; Calkins et al., 1981). Not only do individual muscles differ in fiber-type composition, but muscle fiber type within a specific muscle may be affected by breed (Johnston et al., 1981), sex (Johnston et al., 1975), time on feed (Suzuki et al., 1976), and maturity (Cornforth et al., 1980).

\footnotetext{
${ }^{1}$ Published as paper no. 13332 Journal Series, Nebraska Agric. Res. Div., Univ. of Nebraska, Lincoln 68583-0908. This project was funded in part by beef producers through their $\$ 1$-per-head checkoff and was produced for the Cattlemen's Beef Board and state beef councils by the National Cattlemen's Beef Association.

${ }^{2}$ Correspondence: A213 Animal Sciences, University of Nebraska, Lincoln 68583-0908 (phone: 402-472-6314; fax: 402-472-6362; E-mail: ccalkins1@unl.edu).

${ }^{3}$ Current address: National Cattlemen's Beef Association, 9110 E. Nichols Ave., Centennial, CO 80112.

Received January 10, 2002.

Accepted July 10, 2002.
}

Muscle fiber types have been reported for many of the larger muscles of the beef carcass, such as longissimus dorsi and semitendinosus (Hunt and Hedrick, 1977; Johnston et al., 1981; Manabe et al., 1988), yet little attention has been given to the smaller muscles that comprise the chuck and the round. There is a need to increase the value of the muscles of the beef chuck and round, specifically by increasing the application of smaller muscles into value-added products using further processing techniques (Von Seggern, 2000). With many of these muscles going to further processing, there is a need for a fiber-type profile of these muscles to suggest optimal uses for each muscle. The objectives of this study were to characterize the histochemical muscle fiber type of 12 muscles of the beef round and 26 muscles of the beef chuck, and to evaluate the effect of carcass weight on fiber-type profile.

\section{Materials and Methods}

Chucks $(\mathrm{n}=4)$ and rounds $(\mathrm{n}=4)$ from A-maturity, Select-grade carcasses were chosen from a commercial packing facility to represent two carcass weight ranges (250 to $295 \mathrm{~kg}$ and 363 to $410 \mathrm{~kg}$ ) and two yield grades (yield grades 1 and 3). Twelve muscles of the beef round and 26 muscles of the beef chuck (Jones et 
al., 2001) were fabricated and vacuum packaged prior to shipping to the University of Nebraska meat laboratory. Samples were removed from the center of each muscle to minimize the potential impact of moisture loss during storage and to standardize sampling location within a muscle. Samples were frozen in liquid nitrogen within $9 \mathrm{~d}$ postmortem and subsequently stored at $-81^{\circ} \mathrm{C}$ until histochemical analysis was performed.

One cubic centimeter of frozen tissue was mounted on a cryostat chuck with O.C.T. compound (TissueTEK II, Lab-TEK products, Naperville, IL), an embedding medium used with frozen tissue samples, in such a manner as to set muscle fibers perpendicular to the cutting blade. The mounted cubes were allowed to equilibrate to $-20^{\circ} \mathrm{C}$ before being cut into slices of 12 $\mu \mathrm{m}$ thickness utilizing a Leica Cryocut (Model 1800, Nussloch, Germany) cryostat. The slices were then mounted on slides and allowed to equilibrate to room temperature before being stained.

Muscle sections were stained according to the simultaneous staining method of Solomon and Dunn (1988), which incorporates staining procedures from both $\mathrm{Hu}-$ mason (1972) and Guth and Samaha (1970). First, the samples were stained for succinate dehydrogenase activity using the methodology of Humason (1972). Next, samples were incubated in an acid incubate $(\mathrm{pH}$ 4.15), as stated in Solomon and Dunn (1988). Then, using the method of Guth and Samaha (1970), the samples were stained for acid-active adenosine triphosphatase activity. Cover slips were permanently mounted over the stained tissue for stain preservation.

Fibers were classified on the basis of stain reactions using the technique of Ashmore and Doerr (1971): $\beta$ red fibers were dark brown, $\alpha$-red fibers were clear in the middle and surrounded by a blue ring, and $\alpha$-white fibers were clear. Fiber numbers were calculated by examining a minimum of 500 muscle fibers from muscle bundles containing at least 50 fibers per bundle. Muscle fiber percentage was calculated by counting the total number of each fiber type, dividing by the total number of fibers counted, and multiplying the quotient by 100 .

Muscles were classified as red, intermediate, or white on the basis of the muscle fiber distribution (percent based on number of each fiber type). Muscles were classified as red if they had more than $40 \% \beta$ red fibers, white if they had more than $40 \% \alpha$-white fibers, and all other muscles were classified as intermediate muscles. This is an arbitrary classification. Although the literature is replete with references to red and white muscle, objective classification criteria were not located. At any rate, the actual fiber-type distributions were presented, so other objective classification standards may be applied at a later date.

Fiber diameters were obtained by capturing photomicrograph pictures with a COHU High-Performance CCD camera (Model 4912-2000/0000, COHU, Inc. San
Diego, CA) mounted on a Zeiss Large Universal Research microscope (Zeiss, Germany). Diameters were determined by measuring the smallest apparent diameter across the irregularly shaped fibers. This was done to minimize errors associated with any fibers that may not have been cut exactly perpendicular to fiber direction. A minimum of 50 diameters of each fiber type ( $\beta$-red, $\alpha$-red, and $\alpha$-white) were measured with the help of Scion Image 1.62a based on NIH Image computer software (Center for Image Processing in Education, Tuscon, AZ). Muscle fiber area was calculated from the fiber diameters: $\mathrm{A}=\pi(\text { diameter } / 2)^{2}$, because the software did not allow direct measurement of fiber area. Percent area was calculated for each fiber type by multiplying the average fiber-type number by the average fiber-type area for a specific muscle, dividing by the total area, and multiplying the quotient by 100 .

Data were analyzed using the Proc Mixed Procedure of SAS (SAS Inst., Inc., Cary, NC). Tests of the interaction of muscle and weight and of the simple effects of muscle and weight were used to detect significant variations $(P<0.05)$ in muscle fiber-type characteristics.

\section{Results and Discussion}

Neither weight nor the interaction of weight and muscle were significant for any of the muscle fibertype characteristics studied $(P>0.05)$. The effect of muscle on fiber-type characteristics was always significant $(P<0.002)$. Means were calculated for fibertype distribution (percent based on number of each fiber type), diameter, area, and percentage area. Means are presented by muscle location in Tables 1 and 2 .

It has been noted that fiber-type characteristics are significantly influenced by weight, although this is indirectly associated with an animal's ultimate size (Cornforth et al., 1980; Manabe et al., 1981) and age at slaughter (Suzuki et al., 1976; Manabe et al., 1988). Because muscles used in this experiment were taken from animals of the same carcass maturity, it was thought that the larger animals from the two different weight groups might have significantly larger muscle fiber diameters. Johnston et al. (1975) found a significant increase in muscle fiber diameter in Charolais steers when compared with Angus steers of the same age, especially in $\alpha$-white fibers. In the present study, there were no significant effects of carcass weight on muscle fiber size. However, for two-thirds of the muscles, fiber diameter tended to increase with increasing carcass weight. The lack of significance likely can be attributed to low sample numbers $(n=2)$ per weight group.

The fiber-type characteristics of fiber number (\%), fiber diameter, fiber area, and percent area for each fiber are presented by muscle location (chuck or round) in Tables 1 and 2. Muscle fiber numbers (\%) for specific 
Table 1. Classification and fiber-type composition of muscles from the beef chuck

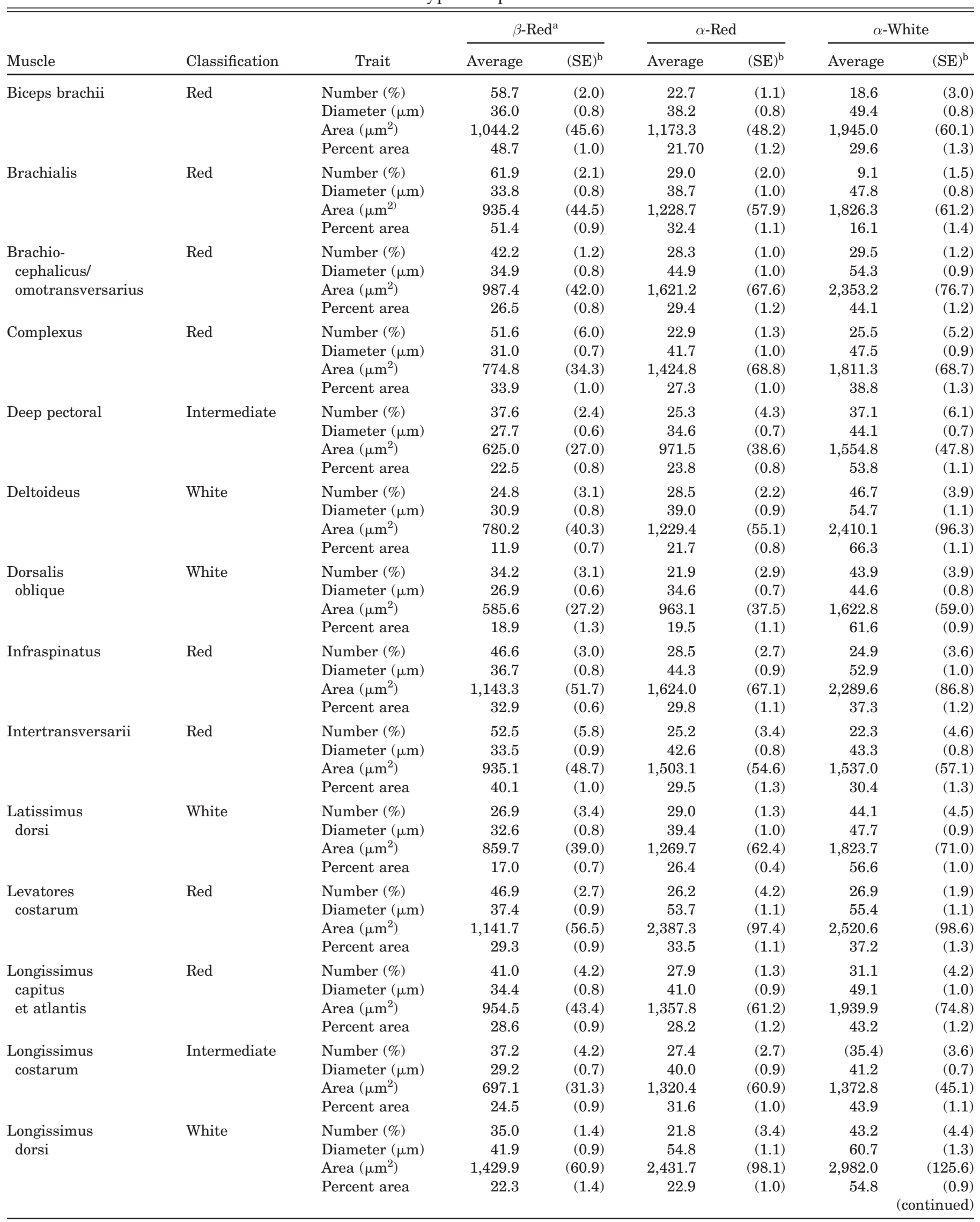


Table 1 (continued). Classification and fiber-type composition of muscles from the beef chuck

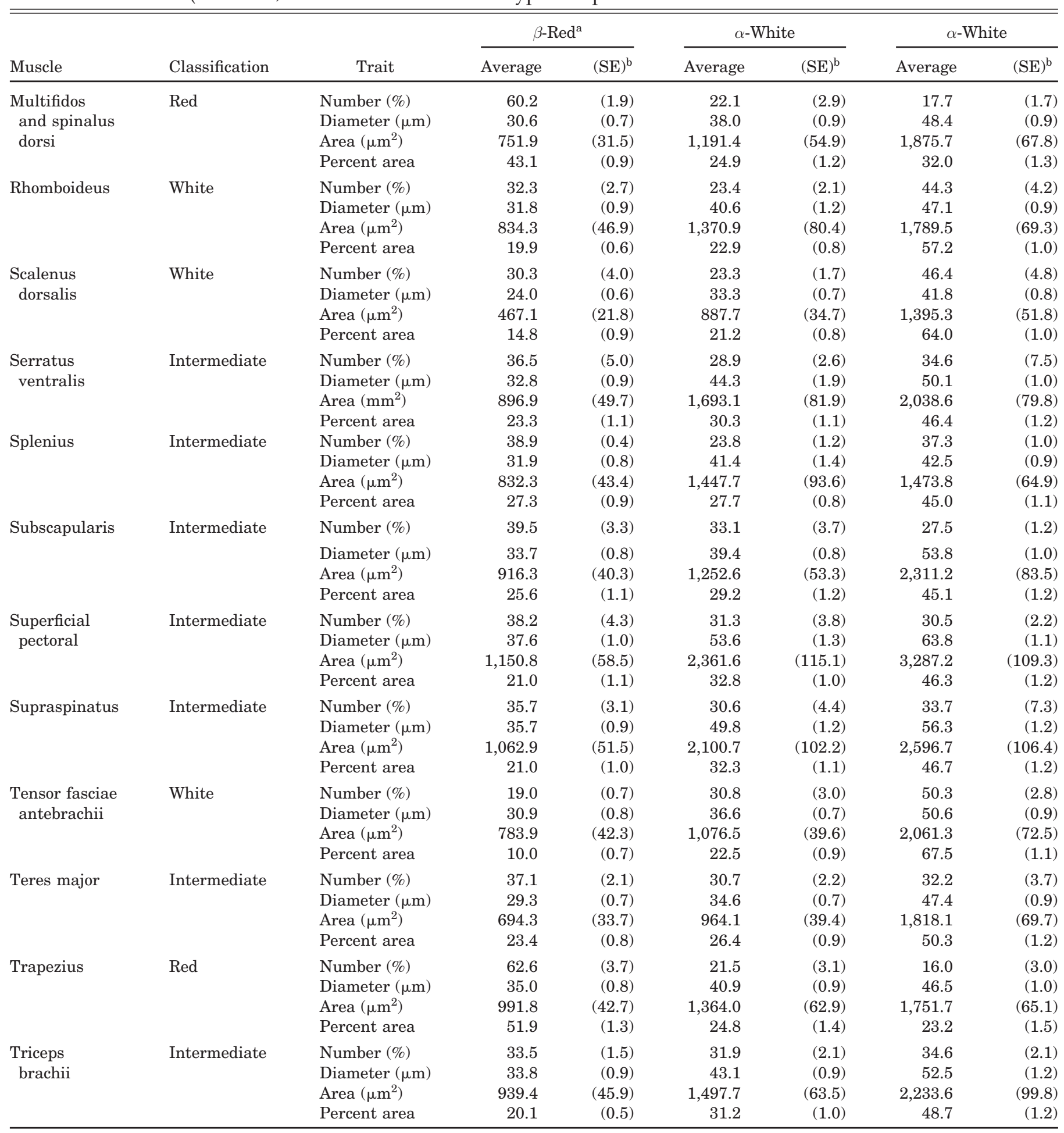

${ }^{\mathrm{a}}$ Muscles containing greater than $40 \% \beta$-red fiber numbers were classified as red.

btandard error of the fiber type traits by muscle.

muscles were similar to those reported by Suzuki et al. (1976), Hunt and Hedrick (1977), Cornforth et al. (1980), and Johnston et al. (1981).

Muscle fiber distribution for triceps brachii were 33.5, 31.9, and 34.6\% ( $\beta$-red, $\alpha$-red, and $\alpha$-white, respectively). These results are similar to those of Suzuki et al. (1976), who reported 29.2, 28.3, and $42.2 \%$
( $\beta$-red, $\alpha$-red, and $\alpha$-white, respectively) in triceps brachii of Holstein steers fed both concentrate and forage diets. Muscle fiber distribution for longissimus dorsi in the present study was $35.0,21.8$, and 43.2 ( $\beta$ red, $\alpha$-red, and $\alpha$-white, respectively). These results are similar to those reported by Hunt and Hedrick (1977), Suzuki et al. (1976), and Johnston et al. (1981), 
Table 2. Classification and fiber-type composition of muscles from the beef round

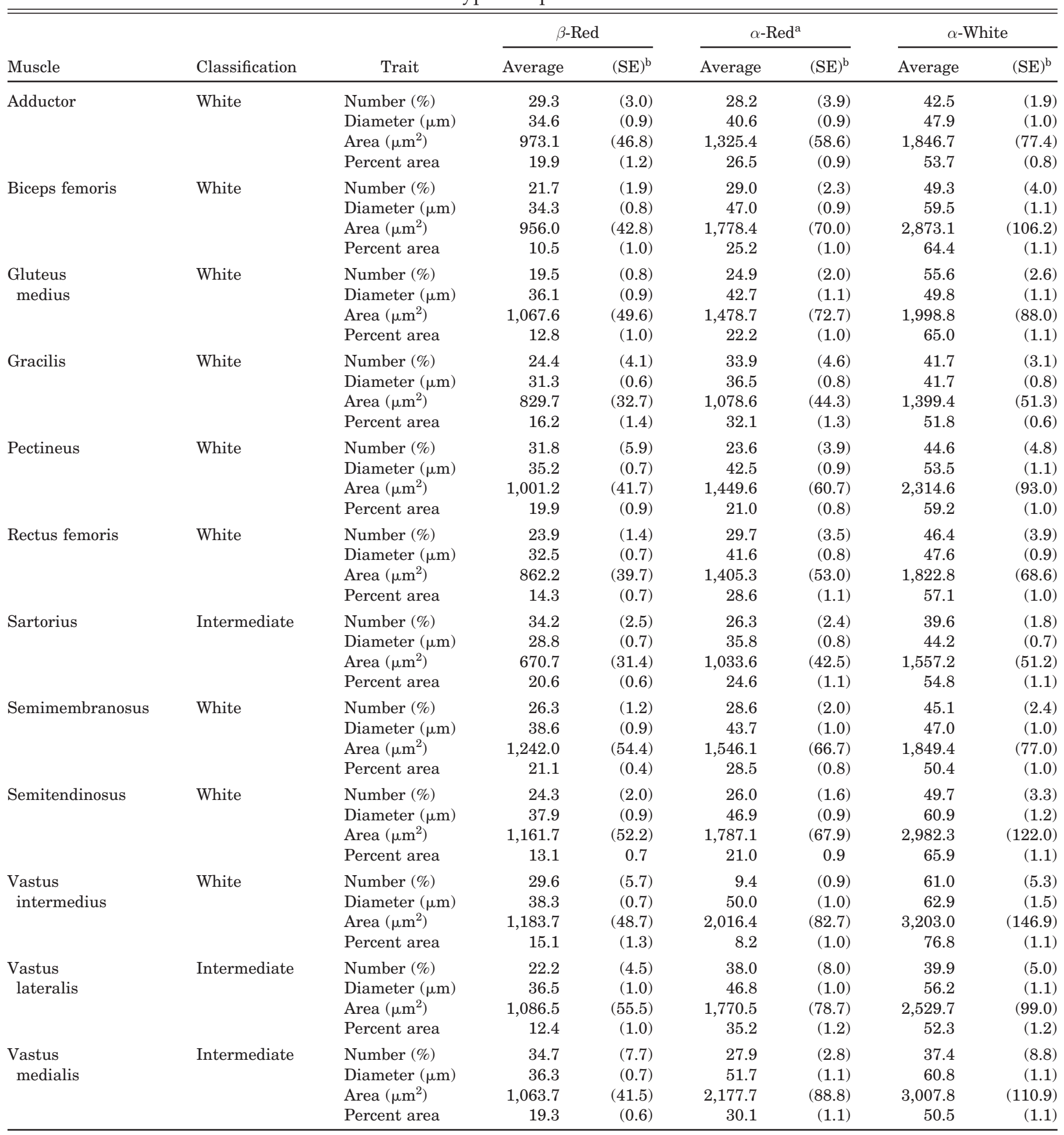

${ }^{a}$ Muscles not classified as red or white were classified as intermediate.

${ }^{\mathrm{b}}$ Standard error of the fiber type traits by muscle.

where fiber-type distribution varied from $46 \% \alpha$-white (Hunt and Hedrick, 1977) in A-maturity, Choice steer carcasses, to $54 \% \alpha$-white (Johnston et al., 1981) in Angus-cross steer and heifer carcasses.

Muscle fiber distribution for gluteus medius was $19.5,24.9$, and $55.6 \%$ ( $\beta$-red, $\alpha$-red, and $\alpha$-white, respectively). These results are similar to those of Hunt and Hedrick (1977), who found 25.8, 21.7, and 52.6\% ( $\beta$-red, $\alpha$-red, and $\alpha$-white, respectively). Distribution of muscle fiber types for biceps femoris were 21.7, 29.0, and $49.3 \%$ ( $\beta$-red, $\alpha$-red, and $\alpha$-white, respectively). These results are also very similar to those reported by Cornforth et al. (1980) and Johnston et al. (1981). Hunt and Hedrick (1977) and Totland et al. (1988) 
found that muscle samples differed in muscle fiber distribution when taken from the surface of the muscle as opposed to deep within the muscle. In this study, samples were removed at a random location in the center of each muscle. Results in fiber distribution from semitendinosus are consistent with measurements made in the interior semitendinosus by Hunt and Hedrick (1977) and Totland et al. (1988), who utilized Norwegian bulls. Similarly, results from semimembranosus $(26.2 \% \beta$-red, $28.6 \% \alpha$-red, and $45.1 \%$ $\alpha$-white) in this study were consistent with measurements made by Suzuki et al. (1976) $(31.8 \% \beta$-red, $14.1 \% \alpha$-red, and $51.1 \% \alpha$-white). Results from Hunt and Hedrick (1977) on the inside $(11.7 \% \beta$-red, $27.8 \%$ $\alpha$-red, and $61.3 \% \alpha$-white) and the outside (15.5\% $\beta$ red, 32.9\% $\alpha$-red, and $51.1 \% \alpha$-white) of the semimembranosus were lower than the percent of $\beta$-red fibers in the present study. This variation may be explained by the fact that the semimembranosus is more irregular in shape than the semitendinosus. The fiber-type number of the semimembranosus may differ in different sections of the muscle due to its nonuniform shape and multiple function.

For the few muscles (longissimus dorsi, biceps femoris, semimembranosus, and semitendinosus) in which fiber areas were available in the literature (Hunt and Hedrick, 1977; Cornforth et al., 1981), our estimates of $\alpha$-red and $\alpha$-white fibers were generally similar (but slightly lower). Our estimates of $\beta$-red fiber areas were lower, partially due to technique. We calculated area from the minimum diameter of the cross-section. Fibers are not completely cylindrical, so our estimates of fiber area could be considered conservative. Others determined area from a photograph and a particle-size analyzer, which allowed measurement of the complete cross-sectional area (Hunt and Hedrick, 1977) or used a projection and grid system to estimate cross-sectional area (Cornforth et al., 1981). Differences in accuracies among methods are common in the field. To futher complicate comparisons, Hunt and Hedrick (1977) observed more than a 30\% range in fiber area from one location within a muscle (the semitendinosus) to another. Taken together, differences in estimated fiber area are not surprising.

Nine of twelve muscles from the round were classified as white (Table 2). The remaining three (vastus medialis, vastus lateralis, and sartorious) were classified as intermediate. In contrast, muscles of the chuck were evenly dispersed between red (10 of 26), intermediate (9 of 26), and white ( 7 of 26 ).

Muscle fiber-type characteristics have been used to explain variation in ultimate meat quality. Calkins et al. (1981) found that marbling increased with a decrease in $\alpha$-white fiber areas. They also reported a significant positive correlation between marbling score and ratios of $\alpha$-white to both $\beta$-red and $\alpha$-red fiber areas, indicating that marbling scores were higher in red oxidative muscles. Hunt and Hedrick (1977) identified muscle fibers classified as $\alpha$-red and $\beta$-red as oxidative in nature and muscle fibers classified as $\alpha$-red and $\alpha$-white as glycolytic. Using this approach, muscles classified as red in this experiment $(>40 \% \beta$ red fibers) were found to be oxidative whereas muscles classified as white ( $>40 \% \alpha$-white fibers) were found to be glycolytic. Muscles classified as intermediate were both oxidative and glycolytic with one noted exception. The vastus lateralis, which was classified an intermediate muscle, was highly glycolytic, attributable to its high percentage of $\alpha$-red and $\alpha$-white fibers (38.0 and 39.9 , respectively). While we classified the vastus lateralis as an intermediate muscle, it may be classified as a white muscle by others.

Muscle fiber-type plays a major role in postmortem tenderization (Dransfield et al., 1981). The aging rate is slower in slow-twitch ( $\beta$-red) muscles than in fasttwitch ( $\alpha$-red and $\alpha$-white) muscles, attributable to increased activity of proteolytic enzymes in fasttwitch muscles (Ouali, 1990; Koohmaraie, 1996). Slow-twitch ( $\beta$-red) muscles have the highest amounts of calpain present, but also have the highest amounts of calpastatin (calpain inhibitor), which prevents proteolysis (Koohmaraie, 1996). High levels of proteinaseinhibitor reduce proteolysis, resulting in slow aging rates postmortem.

Seideman and Theer (1986) used meat from intact, implanted bulls and castrated bulls and reported a positive correlation of percent white fiber number and area with sensory tenderness ratings. They also noted that intermediate fiber number (\%) was negatively correlated with sensory tenderness ratings.

Differences in color stability of muscles can be attributed to muscle type (Hood, 1980). Muscles with a higher proportion of oxidative ( $\beta$-red) fibers will have high concentrations of mitochondria found in the muscle. Intact mitochondria compete for oxygen uptake with myoglobin, thus creating a large flux in muscle color, reducing the depth of the oxymyoglobin layer, and creating dark muscle appearance (reviewed by Monin and Ouali, 1992). These results suggest that muscles classified as red would have faster rates of discoloration and increased metmyoglobin production under aerobic display.

\section{Implications}

The results of this study reveal a wide variation among muscles of the chuck, while round muscles are predominantly white. The variation in the fiber-type characteristics of the muscles of the chuck would be expected to impact the functional properties of the muscles when used in further processing such as muscle color, color stability, tenderness, and ultimate muscle pH. Functional properties of the muscles of the beef round would not be expected to vary widely as a consequence of fiber-type composition when used in further processing applications. 


\section{Literature Cited}

Ashmore, C. R. 1974. Phenotypic expression of muscle fiber types and some implications to meat quality. J. Anim. Sci. 38:1158-1164.

Ashmore, C. R., and L. Doerr. 1971. Comparative aspects of muscle fiber types in different species. Exp. Neurol. 31:408-418.

Calkins, C. R., T. R. Dutson, G. C. Smith, Z. L. Carpenter, and G. W. Davis. 1981. Relationship of fiber type composition to marbling and tenderness of bovine muscle. J. Food Sci. 46:708-710.

Cassens, R. G., and C. C. Cooper. 1971. Red and White Muscle. Adv. Food Res. 19:1.

Cornforth, D. P., A. L. Hecker, D. A. Cramer, A. A. Spindler, and M. M. Mathias. 1980. Maturity and its relationship to muscle characteristics of cattle. J. Anim. Sci. 50:75-80.

Dransfield, E., R. C. D. Jones, and H. J. H. MacFie. 1981. Quantifying changes in tenderness during storage of beef. Meat Sci. 5:131-137.

Guth, L., and F. J. Samaha. 1970. Procedure for the histochemical demonstration of actomyosin ATPase. Exp. Neurol. 28:365.

Hood, D. E. 1980. Factors affecting the rate of metmyoglobin accumulation in pre-packaged beef. Meat Sci. 4:247.

Humason, G. L. 1972. Animal Tissue Techniques. 3rd ed. p 444. W.H. Freeman and Company. San Francisco, CA.

Hunt, M. C., and H. B. Hedrick. 1977. Profile of fiber types and related properties of five bovine muscles. J. Food Sci. 42:513-517.

Jones, S. J., D. E. Burson, and C. R. Calkins. 2001. Muscle profiling and bovine mycology. Online. Available: http://deal.unl.edu/ bovine/. Accessed May 13, 2002.

Johnston, D. M., W. G. Moody, J. A. Boling, and N. W. Bradley. 1981. Influence of breed type, sex, feeding systems, and muscle bundle size on bovine fiber type characteristics. J. Food Sci. 46:1760-1765.

Johnston, D. M., D. F. Stewart, W. G. Moody, J. Boling, and J. D. Kemp. 1975. Effect of breed and time on feed on the size and distribution of beef muscle fiber types. J. Anim. Sci. 40:613620.

Koohmaraie, M. 1996. Biochemcial factors regulating the toughnening and tenderisation process of meat. Meat Sci. 43:193-201.

Manabe, N., T. Ishibashi, K. Namikawa, and T. Fukushima. 1981. Difference in fiber diameter of twenty muscles among Japanese black and Holstein cattle, and their crossbreds. Mem. Coll. Agric., Kyoto Univ. 119:63-73.

Manabe, N., T. Ishii, and T. Ishibashi. 1988. Histochemical fiber type composition and fiber size in skeletal muscles of the growing cattle, sheep and swine. Mem. Coll. Agric., Kyoto Univ. 131:27-36.

Melton, C. C., M. E. Dikeman, H. J. Tuma, and D. H. Kropf. 1975. Histochemical relationships of muscle biopsies with bovine muscle quality and composition. J. Anim. Sci. 40:451-456.

Melton, C. C., M. E. Dikeman, H. J. Tuma, and R. R. Schalles. 1974. Histological relationships of muscle biopsies to bovine meat quality and carcass composition. J. Anim. Sci. 38:24-31.

Monin, G., and A. Ouali. 1992. Muscle differentiation and meat quality. Pages 89-157 in Developments in Meat Science. 5th ed. R. Lawrie, ed. Elsevier Applied Science, London.

Ouali, A. 1990. Meat tenderization: Possible causes and mechanisms. A Review. J. Muscle Foods 1:129-165.

Seideman, S. C., and L. K. Theer. 1986. Relationships of instrumental textural properties and muscle fiber types to the sensory properties of beef. J. Food Qual. 9:251-261.

Solomon, M. B., and M. C. Dunn. 1988. Simultaneous histochemical determination of three fiber types in single sections of ovine, bovine and porcine skeletal muscle. J. Anim. Sci. 66:255-264.

Suzuki, A., H. Tamate, and M. Okada. 1976. The effect of a high plane of nutrition during a given period of growth on size and proportion of skeletal muscle fiber types in the cattle. Tohuko J. Agric. Res. 27:20-25.

Totland, G. K., H. Kryvi, and E. Slinde. 1988. Composition of muscle fiber types and connective tissue in bovine M. semitendinosus and its relation to tenderness. Meat Sci. 23:303-315.

Von Seggern, D. 2000. Characterization of the muscles of the beef chuck and round. M. S. Thesis, Univ. Nebraska, Lincoln. 